\title{
BMJ Open Benefits of family planning: an assessment of women's knowledge in rural Western Kenya
}

\author{
Namuunda Mutombo, ${ }^{1}$ Pauline Bakibinga, ${ }^{2}$ Carol Mukiira, ${ }^{1}$ Eva Kamande ${ }^{2}$
}

To cite: Mutombo N, Bakibinga P, Mukiira C, et al. Benefits of family planning: an assessment of women's knowledge in rural Western Kenya. BMJ Open 2014;4: e004643. doi:10.1136/ bmjopen-2013-004643

- Prepublication history for this paper is available online. To view these files please visit the journal online (http://dx.doi.org/10.1136/ bmjopen-2013-004643).

Received 9 December 2013 Revised 3 February 2014 Accepted 27 February 2014

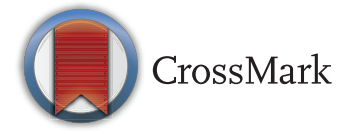

${ }^{1}$ Population Dynamics and Reproductive Health Research Program, African Population \& Health Research Center, Nairobi, Kenya

${ }^{2}$ Health Challenges and Systems Research Program, African Population \& Health Research Center, Nairobi, Kenya

Correspondence to Dr Namuunda Mutombo; nmutombo@aphrc.org

\section{ABSTRACT}

Background: The last two decades have seen an increase in literature reporting an increase in knowledge and use of contraceptives among individuals and couples in Kenya, as in the rest of Africa, but there is a dearth of information regarding knowledge about benefits of family planning (FP) in Kenya.

Objectives: To assess the factors associated with knowledge about the benefits of FP for women and children, among women in rural Western Kenya.

Methods: Data are drawn from the Packard Western Kenya Project Baseline Survey, which collected data from rural women (aged 15-49 years). Ordinal regression was used on 923 women to determine levels of knowledge and associated factors regarding benefits of FP.

Results: Women in rural Western Kenya have low levels of knowledge about benefits of FP and are more knowledgeable about benefits for the mother rather than for the child. Only age, spousal communication and type of contraceptive method used are significant. Conclusions: Women's level of knowledge about benefits of FP is quite low and may be one of the reasons why fertility is still high in Western Kenya. Therefore, FP programmes need to focus on increasing women's knowledge about the benefits of FP in this region.

\section{BACKGROUND}

The last two decades have seen an increase in literature reporting an increase in knowledge and use of contraceptives among individuals and couples in Kenya, as in the rest of sub-Saharan Africa, but there is a dearth of information regarding knowledge about the benefits of family planning (FP) in Kenya. In Kenya, knowledge of FP is almost universal at $95 \%$ for women of reproductive age, with male condoms, injecTable contraceptives and pills being the most commonly known methods. ${ }^{1}$ FP use has in the last two decades also increased from $18 \%$ (1987) to $39 \%$ $(2008 / 09) .{ }^{1}$ However this increase has not been matched with a reduction in the unmet

\section{Strengths and limitations of this study}

- This study has affirmed the importance of information provision about the benefits of family planning and the potential role of involving men in up-scaling the uptake of family planning methods in Western Kenya.

- However, like any other quantitative study, the paper does not bring out the actual stories behind these statistics.

need for FP or reduction in fertility rates. The unmet need for FP in Kenya has stalled at around $25 \%$ and is highest among the less economically well-off women and those in rural areas. ${ }^{2}$ Total fertility rate in rural areas has remained unchanged at 5.2. In addition, at the national level, only a slight decrease in fertility has been reported from 4.7 in 1998 to 4.6 in $2008 / 09 .^{2}$ There are regional variations in fertility trends in Kenya. Fertility is highest in Nyanza and Western provinces at 5.6 and 5.4, respectively. ${ }^{1}$ Married women in the rural areas of Kenya use modern methods of FP $(37 \%)$ less than women in urban areas $(47 \%){ }^{1}$

FP has several benefits, some of which are specific to the health of mothers and their children. Others include socioeconomic benefits; for example, women are able to advance their education and careers by delaying or limiting childbearing and this can bring better economic prospects to their household. ${ }^{3}{ }^{4}$ FP serves to reduce child and maternal morbidity and mortality by preventing unintended pregnancies and unsafe abortions. ${ }^{5}$ The number of maternal deaths that could be averted during childbirth as a result of a reduction in the number of pregnancies and induced abortions would be significant. ${ }^{6}$ FP also enables birth spacing, ultimately reducing child mortality while enhancing the nutritional status of both mother and child. ${ }^{4}$ Moreland and Talbird's ${ }^{5}$ analysis of the role of contraception use to 
the Millennium Development Goals showed that fulfilling the unmet need for FP in Kenya will prevent maternal mortality and child mortality by 14040 and 434306 deaths, respectively, and reduce poverty. ${ }^{7}$ Consequently this could contribute to significantly empowering women, achieving universal education for all, and achieving long term environmental sustainability. ${ }^{8}$

Several studies have assessed women's and couples' knowledge about, and use of contraceptives, in addition to barriers to the uptake of FP services. ${ }^{9-11}$ A study conducted in Bondo District of Western Kenya found that few women knew that FP prevented conception, enabled child spacing, reduced the risk of acquiring and transmitting sexually transmitted infections and helped avoid high-risk pregnancies. ${ }^{9}$ Cultural beliefs, fear of side effects, disapproval by couples and inadequate knowledge about contraceptive methods and their benefits are major barriers to contraceptive uptake. ${ }^{9} 12{ }^{13}$ Women with knowledge about contraceptives and the benefits of FP are more likely to use contraceptives. ${ }^{4}$ Knowledge enables women to make informed decisions about what contraceptives to use and when to use them. ${ }^{4}$

As noted earlier, the Western region of Kenya has poor reproductive health indicators. In response to this need, the Packard Western Kenya Project (PWKP) with financial support from the David and Lucile Packard Foundation, was launched in 2010 in line with the National Reproductive Health Strategy (2009-2015), which, among other aims, seeks to involve communities in enhancing the health of the population through interventions implemented at community level. The PWKP is being implemented in the region with an ultimate goal of reducing unwanted and mistimed pregnancies, lowering the incidence of unsafe, illegal abortion, reducing maternal morbidity and mortality, and decreasing fertility rates over time. These goals are to be met by increasing routine use of modern contraceptive methods among women of reproductive age in Western Kenya. In 2010, a baseline survey was designed to provide information on key programme elements for subsequent monitoring and evaluation of the performance of the PWKP. As part of the baseline, the women were asked what they perceived as the impacts of FP on both women and children. In this paper we analyse the factors associated with knowledge about the benefits of FP for women and children.

\section{DATA AND METHODS}

\section{Data source and sample design}

This was an exploratory study, which employed data from a cross-sectional baseline sample of the PWKP Baseline Survey (PWKPBS). The PWKPBS collected data from rural women aged 15-49 years. All study participants were required to give consent before taking part in the research. For women aged 15-18, interviewers sought further consent from the parents or guardian of the respondent. The face to face interviews were conducted in a private place to protect the confidentiality of responses and enhance the comfort of respondents. The questionnaire used was translated into the commonly spoken languages in the study area. This study was approved by the Kenya Medical Research Institute (KEMRI) Ethics Review Committee. The African Population and Health Research Center implemented the 2010 household baseline survey for the PWKP, in collaboration with the Kenya National Bureau of Statistics (KNBS), and the Great Lakes University of Kisumu (GLUK), using 36 interviewers. A representative multi-stage sample of 2125 households from 60 enumeration areas distributed proportionally among four districts (Bondo, Busia, Siaya and Teso) was drawn for the survey using the frame of the 2008 KNBS. Data collection took approximately 2 weeks; a total of 1997 women were interviewed, representing a response rate of $86 \%$. However, $54 \%$ of these women were excluded from analyses in this paper as they did not know a method of FP.

Some of the criteria considered for an individual to be included in the survey were age (15-29), the ability to communicate in the survey languages and availability to participate in the survey.

\section{Variables}

Two dependent variables are used in this paper: level of knowledge about FP benefits for the child; and level of knowledge about FP benefits for the mother, also referred to as Model I and Model II in table 5, respectively. Since the ordered logit models used require the dependent variable to have three outcomes, the two dependent variables were recoded into trichotomous variables. These variables were constructed based on responses to a series of questions on the impact of FP on the mother and child (see tables 1 and 2). The information in figure 1 was used to construct the first dependent variable. Each correct response was assigned a code of 1 while each incorrect response was assigned a code of 0 . All respondents who scored 0 on all questions had the final score of 0 and were coded as having no knowledge or classified into the 'none' category. All respondents who scored 1 out of 7 were coded as having 'low' knowledge level. Scores 2-7 were coded as 'high' knowledge category. The categorisation of scores was based on relative scores and was also aimed at minimising skewness in the dependent variable as the majority of respondents had low scores (see figure 1). The scores ranged between 0 and 5 with a median score of 2 . In the strict sense, for example, persons who scored 2 out of 7 had a low score but were categorised as high in order to distinguish them from those with 0 and 1 scores.

Information in figure 2 was used to construct the second dependent variable. Similarly, in the construction of the second dependent variable, we assigned a code of 1 for each correct response. Each incorrect response was assigned a code of 0 . All respondents who scored 0 on all questions had the final score of 0 and were coded as having no knowledge or classified into 
the 'none' knowledge level category. All respondents who scored 1-3 out of 12 were coded as having 'low' knowledge level. Scores 4-12 were coded as 'high' knowledge category. The scores ranged between 0 and 8 out of 12 with a median score of 2 .

A total of 12 independent variables were included in the analyses (see tables 1-3). Marital status was excluded from the analytical models as less than 20 women were not married. Women of ethnicities other than Luhya, Luo and Teso were also excluded from the analyses as they were very few $(<30)$.

\section{Data analysis}

Frequencies, cross-tabulations and the ordered logit were used to analyse levels and differentials in knowledge levels among women (aged 15-49) in Western Kenya. Ordinal regression depends on the idea of the cumulative logit, which in turn relies on the idea of the cumulative probability. ${ }^{14}{ }^{15}$ The cumulative probability can be thought of as the probability that the $i$ th individual is in the $j$ th or higher category. This can be expressed as:

$$
\mathrm{C}_{\mathrm{ij}}=\operatorname{Pr}\left(\mathrm{y}_{\mathrm{i}} \leq \mathrm{j}\right)=\sum_{\mathrm{k}=1}^{\mathrm{j}} \operatorname{Pr}\left(\mathrm{y}_{\mathrm{i}}=\mathrm{k}\right)
$$

where $\mathrm{y}=$ dependent variable (level of knowledge about impact of FP); and k=values of y (1., 2., 3.,...n).

The cumulative probability above can be transformed into the cumulative ordered logit:

$$
\operatorname{Logit}\left(\mathrm{C}_{\mathrm{ij}}\right)=\log \left[\mathrm{C}_{\mathrm{ij}} /\left(1-\mathrm{C}_{\mathrm{ij}}\right)\right]=\alpha_{\mathrm{ij}}-\beta_{\mathrm{ij}}
$$

where: $\alpha_{\mathrm{j}}=\operatorname{logit}$ of the odds of being equal to or less than category $j$ for the baseline group (also referred to as intercepts or cut-points); and $\beta=$ the increase in the log-odds of being higher than category $j$ per one-unit increase in the independent variable.

A negative $\beta$ coefficient shows lower log-odds of having higher than lower knowledge about the impacts of FP on the child/mother compared with the reference

Table 1 Distribution of respondents by knowledge about the impact of family planning on the child

\begin{tabular}{lrll}
\hline What is the impact on the child & \multicolumn{3}{c}{ Response (\%) } \\
\cline { 2 - 4 } if the mother uses family & & & \\
planning? & 52.7 & 45.9 & 1.4 \\
\hline Better growth & 23.1 & 75.3 & 1.6 \\
Better nutritional status & 43.9 & 54.6 & 1.5 \\
Better health & 8.5 & 89.8 & 1.7 \\
Better survival chance & 39.3 & 59.3 & 1.5 \\
Better attention by mother & 22.8 & 75.5 & 1.7 \\
Better educated & 10.7 & 87.6 & 1.7 \\
More opportunities & & &
\end{tabular}

Table 2 Distribution of respondents by knowledge about

\begin{tabular}{|c|c|c|c|}
\hline \multirow{2}{*}{$\begin{array}{l}\text { What is the impact on the } \\
\text { mother if she uses family } \\
\text { planning? }\end{array}$} & \multicolumn{3}{|c|}{ Response (\%) } \\
\hline & Yes & No & Missing \\
\hline $\begin{array}{l}\text { Easy to space pregnancies/ } \\
\text { children }\end{array}$ & 45.2 & 53.4 & 1.4 \\
\hline Better nutritional status & 16.5 & 82.2 & 1.3 \\
\hline Lower incidence of anaemia & 2.3 & 96.1 & 1.7 \\
\hline Less pregnancy complications & 5.3 & 93.2 & 1.5 \\
\hline Avoids STI/HIV & 0.8 & 97.6 & 1.6 \\
\hline Reduces unwanted pregnancies & 20.1 & 78.5 & 1.4 \\
\hline Better health & 28.9 & 69.6 & 1.5 \\
\hline $\begin{array}{l}\text { Spousal harmony/marital } \\
\text { happiness }\end{array}$ & 3.3 & 95.1 & 1.6 \\
\hline Fewer children to educate & 23.3 & 75.2 & 1.5 \\
\hline She has more free time & 38.2 & 60.3 & 1.5 \\
\hline Family has more money & 6.8 & 91.6 & 1.6 \\
\hline Peace of mind & 17.1 & 81.5 & 1.4 \\
\hline
\end{tabular}
the impact of family planning on the mother

category (ie, lower knowledge than the reference category). On the other hand, a positive coefficient indicates higher log-odds of having higher than lower knowledge about the impacts of FP on the child/mother compared with the reference category (ie, higher knowledge than the reference category). Exponentiation of $\beta$ coefficients yields ORs (not shown in tables).

\section{RESULTS}

\section{Descriptive characteristics of respondents}

Results from only 923 (46\%) women (aged 15-49) out of the 1997 women interviewed were valid for the regression analyses; characteristics of the women are shown in table 3 . The rest $(54 \%)$ did not know a method of FP, hence their exclusion. Most (83\%) women in this sample had access to the radio while a quarter had access to television and newspapers/magazines. By age, the majority $(49 \%)$ of women were aged 25-39 years and the rest were aged 15-24 (30\%) and 40-49 (21\%). The frequency distributions in table 3 also confirm other observations about high fertility in this region of

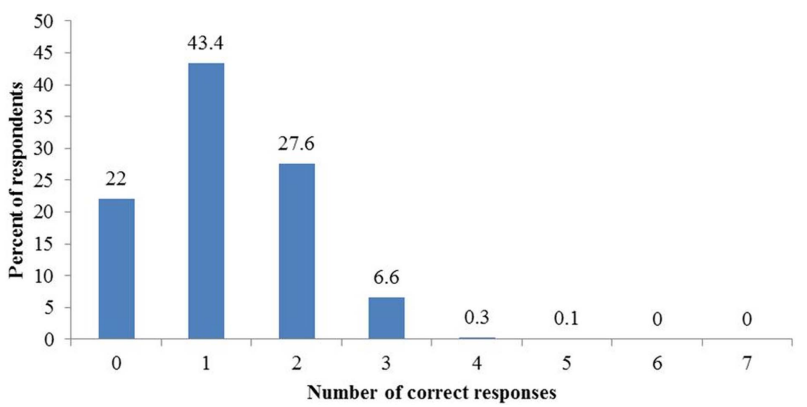

Figure 1 Percentage distribution of respondents according to number of correct responses to questions about the impact of family planning on the child $(n=1965)$. 


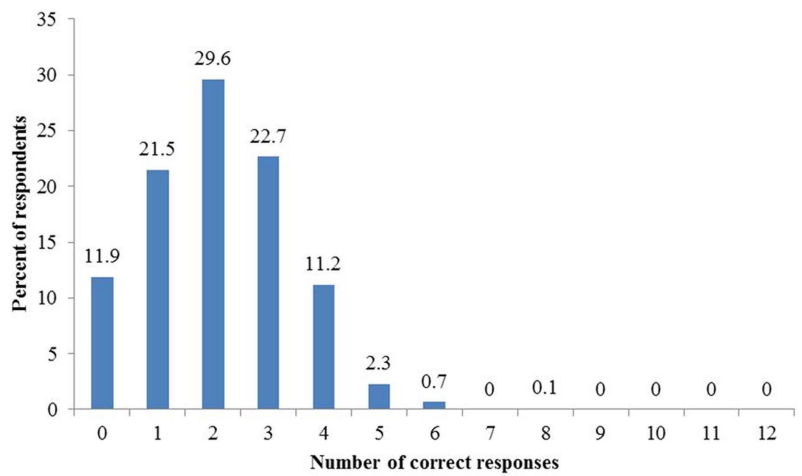

Figure 2 Percentage distribution of respondents according to number of correct responses to questions about the impact of family planning on the mother $(n=1965)$.

Kenya as more than half the women had four or more children ever born.

Luo women were the majority $(58 \%)$, followed by Luhya women who comprised a quarter of the entire sample size. Catholics were a minority when compared to non-Catholics; $32 \%$ vs $68 \%$, respectively. Education levels are quite low among these women. Approximately $80 \%$ had not received education beyond primary education. A similar pattern is observed among their partners: less than $40 \%$ of the women had partners who had some post-primary education. Table 1 , however, also shows that the majority $(68 \%)$ of women reported discussing FP with their partner/husband even though almost half $(49 \%)$ of the sample were not using a method of contraception at the time of the survey. Strikingly, the majority of women reporting current use of contraception were using a long-acting or permanent method of contraception. According to district, more than a third $(38 \%)$ of the women surveyed were from Siaya district while the smallest sample was drawn from Bondo district (19\%).

According to the level of knowledge about the impact of using FP on the child, which is one of the dependent variables for this paper, the majority of women had none or low level of knowledge. Less than $40 \%$ of women were in the high level knowledge category. Concerning the level of knowledge about the impact of using FP on the mother, data indicated some relatively higher knowledge for impact on the mother than on the child (see table 1).

Factors associated with knowledge about the impact of using FP methods on children and women

A higher proportion of women had some knowledge about the impact of using FP on the mother than on the child. Seventeen per cent of the women had no knowledge at all about the impact on the child while only $6 \%$ exhibited a total lack of knowledge about the impact of FP on the mother. The results in table 4 show some significant associations between the level of knowledge about the impact of FP and some characteristics.

\begin{tabular}{|c|c|c|}
\hline Characteristics & $\%$ & $\mathbf{n}$ \\
\hline \multicolumn{3}{|l|}{ Age (years) } \\
\hline $15-24$ & 30.3 & 280 \\
\hline $25-39$ & 48.6 & 449 \\
\hline $40-49$ & 21.0 & 194 \\
\hline \multicolumn{3}{|l|}{ Parity } \\
\hline$<2$ & 15.1 & 139 \\
\hline $2-3$ & 28.7 & 265 \\
\hline $4-5$ & 26.4 & 244 \\
\hline $6+$ & 29.8 & 275 \\
\hline \multicolumn{3}{|l|}{ Ethnicity } \\
\hline Luhya & 25.0 & 231 \\
\hline Luo & 57.7 & 533 \\
\hline Teso & 17.2 & 159 \\
\hline \multicolumn{3}{|l|}{ Religion } \\
\hline Catholic & 30.6 & 282 \\
\hline Other & 69.4 & 641 \\
\hline \multicolumn{3}{|l|}{ Level of education } \\
\hline$<$ Secondary & 79.8 & 737 \\
\hline Secondary+ & 20.2 & 186 \\
\hline \multicolumn{3}{|l|}{ Partner's level of education } \\
\hline$<$ Secondary & 61.0 & 563 \\
\hline Secondary+ & 39.0 & 360 \\
\hline \multicolumn{3}{|c|}{ Reads newspapers or magazines } \\
\hline Yes & 25.4 & 234 \\
\hline No & 74.6 & 689 \\
\hline \multicolumn{3}{|l|}{ Listens to radio } \\
\hline Yes & 83.7 & 773 \\
\hline No & 16.3 & 150 \\
\hline \multicolumn{3}{|l|}{ Watches television } \\
\hline Yes & 23.0 & 212 \\
\hline No & 77.0 & 711 \\
\hline \multicolumn{3}{|c|}{ Discussed use of FP with spouse } \\
\hline Yes & 68.9 & 636 \\
\hline No & 31.1 & 287 \\
\hline \multicolumn{3}{|l|}{ Type of FP method being used } \\
\hline None & 49.4 & 456 \\
\hline Short-acting & 16.1 & 149 \\
\hline Long-acting or permanent & 34.5 & 318 \\
\hline \multicolumn{3}{|l|}{ District } \\
\hline Bondo & 19.2 & 177 \\
\hline Siaya & 38.2 & 353 \\
\hline Busia & 22.1 & 204 \\
\hline Teso & 20.5 & 189 \\
\hline \multicolumn{3}{|c|}{ Level of knowledge about FP benefits for the child } \\
\hline None & 17.3 & 160 \\
\hline Low & 46.4 & 428 \\
\hline High & 36.3 & 335 \\
\hline \multicolumn{3}{|c|}{ Level of knowledge about FP benefits for the mother } \\
\hline None & 5.9 & 54 \\
\hline Low & 78.5 & 724 \\
\hline High & 15.7 & 145 \\
\hline Total & 100.0 & 923 \\
\hline
\end{tabular}

The variables age, parity, partner's level of education, discussion of FP with partner and contraceptive use have the strongest association with knowledge about the 
impact of FP on the child. Age and level of knowledge regarding the impact of $\mathrm{FP}$ on the child have a positive linear correlation, that is, the older the woman, the higher the level of knowledge. Similarly, women with a higher number of children $(>3)$ have a higher knowledge about the impact of FP on the child than women with a smaller number of children $(<4)$. As expected, women who reported having partners with lower than secondary education level have a lower level of knowledge than women whose partner had secondary or higher level of education. Interestingly, women's own level of education was less significant than partner's education level on their knowledge about the impact of using FP on the child, suggesting the influential role their partner's characteristics may pose on women. Women who reported that they discussed FP with their partners and those using a method of FP (either short or long term) exhibited higher knowledge about the

Table 4 Prevalence of knowledge about the impact of family planning (FP) on mother and child among women (aged 15-49 years) in Nyanza and Western Regions of Kenya

\begin{tabular}{|c|c|c|c|c|c|c|}
\hline \multirow[b]{2}{*}{ Characteristics of respondents } & \multicolumn{3}{|c|}{$\begin{array}{l}\text { Knowledge about impact of FP } \\
\text { on the child }\end{array}$} & \multicolumn{3}{|c|}{$\begin{array}{l}\text { Knowledge about impact of FP } \\
\text { on the mother }\end{array}$} \\
\hline & None & Low & High & None & Low & High \\
\hline Age (years) & $p=0.000$ & & & $p=0.000$ & & \\
\hline $15-24$ & 28.3 & 43.0 & 28.7 & 18.8 & 71.8 & 9.4 \\
\hline $25-39$ & 18.0 & 44.5 & 37.6 & 6.0 & 76.7 & 17.3 \\
\hline $40-49^{\star}$ & 16.7 & 42.0 & 41.3 & 8.6 & 72.7 & 18.7 \\
\hline Parity & $p=0.000$ & & & $p=0.000$ & & \\
\hline$<2$ & 29.1 & 42.4 & 28.5 & 21.0 & 68.5 & 10.4 \\
\hline $2-3$ & 22.4 & 46.8 & 30.9 & 8.7 & 79.4 & 11.9 \\
\hline $4-5$ & 15.8 & 41.4 & 42.7 & 5.3 & 74.7 & 20.1 \\
\hline $6+^{\star}$ & 17.3 & 43.1 & 39.6 & 8.0 & 75.1 & 16.9 \\
\hline Ethnicity & $\mathrm{p}=0.001$ & & & $p=0.000$ & & \\
\hline Luhya & 22.5 & 39.9 & 37.6 & 9.3 & 76.0 & 14.7 \\
\hline Luo & 19.3 & 47.3 & 33.4 & 8.6 & 76.3 & 15.1 \\
\hline Teso* & 27.0 & 38.1 & 34.9 & 21.8 & 65.8 & 12.4 \\
\hline Religion & $\mathrm{p}=0.191$ & & & $p=0.035$ & & \\
\hline Catholic & 24.1 & 40.8 & 35.1 & 14.6 & 71.5 & 13.9 \\
\hline Other* & 21.1 & 44.6 & 34.4 & 10.6 & 75.0 & 14.4 \\
\hline Level of education & $\mathrm{p}=0.011$ & & & $p=0.000$ & & \\
\hline$<$ Secondary & 23.1 & 43.8 & 33.1 & 13.2 & 73.2 & 13.6 \\
\hline Secondary+* & 16.7 & 44.5 & 38.8 & 6.4 & 74.9 & 18.7 \\
\hline Partner's level of education & $p=0.000$ & & & $p=0.094$ & & \\
\hline$<$ Secondary & 19.2 & 45.0 & 35.8 & 8.1 & 77.8 & 14.1 \\
\hline Secondary $+^{*}$ & 16.9 & 45.4 & 37.7 & 5.2 & 77.9 & 16.9 \\
\hline Reads newspapers or magazines & $\mathrm{p}=0.472$ & & & $p=0.024$ & & \\
\hline Yes & 23.2 & 41.2 & 35.6 & 12.8 & 69.8 & 17.4 \\
\hline $\mathrm{No}^{*}$ & 21.6 & 44.2 & 34.2 & 11.6 & 75.4 & 13.1 \\
\hline Listens to radio & $\mathrm{p}=0.228$ & & & $p=0.004$ & & \\
\hline Yes & 21.3 & 43.3 & 35.4 & 11.6 & 72.8 & 15.6 \\
\hline $\mathrm{No}^{*}$ & 24.6 & 43.7 & 31.6 & 13.0 & 77.8 & 9.2 \\
\hline Watches television & $\mathrm{p}=0.148$ & & & $p=0.008$ & & \\
\hline Yes & 21.9 & 39.8 & 38.2 & 10.9 & 70.4 & 18.8 \\
\hline $\mathrm{No}^{*}$ & 22.1 & 44.4 & 33.6 & 12.2 & 74.9 & 12.9 \\
\hline Discussed use of FP with spouse & $p=0.000$ & & & $p=0.000$ & & \\
\hline Yes & 14.6 & 46.0 & 39.4 & 3.8 & 79.1 & 17.1 \\
\hline $\mathrm{No}^{*}$ & 26.9 & 43.7 & 29.4 & 14.7 & 74.4 & 10.9 \\
\hline Type of FP method being used & $\mathrm{p}=0.000$ & & & $p=0.000$ & & \\
\hline None & 24.3 & 44.9 & 30.8 & 14.8 & 73.2 & 12.1 \\
\hline Short-acting & 17.6 & 40.4 & 42.0 & 7.1 & 74.5 & 18.4 \\
\hline Long-acting or permanent & 12.6 & 46.4 & 41.0 & 1.1 & 80.9 & 17.9 \\
\hline District & $\mathrm{p}=0.001$ & & & $p=0.000$ & & \\
\hline Bondo & 20.7 & 44.6 & 34.7 & 9.6 & 74.6 & 15.9 \\
\hline Siaya & 18.9 & 49.5 & 31.6 & 8.0 & 77.6 & 14.4 \\
\hline Busia & 23.5 & 37.2 & 39.3 & 9.6 & 75.5 & 15.0 \\
\hline Teso* $^{*}$ & 25.6 & 40.5 & 33.9 & 20.6 & 67.1 & 12.3 \\
\hline
\end{tabular}


Table 5 Log-odds of having higher than lower knowledge about the impact of family planning (FP) on women (aged 15-49 years) in Nyanza and Western Regions of Kenya by selected characteristics

\begin{tabular}{|c|c|c|c|c|}
\hline \multirow[b]{2}{*}{ Characteristics of respondents } & \multicolumn{2}{|l|}{ Model I } & \multicolumn{2}{|l|}{ Model II } \\
\hline & $\bar{\beta}$ & p Value & $\bar{\beta}$ & p Value \\
\hline \multicolumn{5}{|l|}{ Age (years) } \\
\hline $15-24$ & -0.127 & 0.596 & -0.925 & 0.003 \\
\hline 25-39 & -0.118 & 0.508 & -0.231 & 0.306 \\
\hline $40-49^{*}$ & - & - & - & - \\
\hline \multicolumn{5}{|l|}{ Parity } \\
\hline$<2$ & 0.098 & 0.700 & 0.223 & 0.508 \\
\hline $2-3$ & -0.117 & 0.567 & 0.053 & 0.842 \\
\hline $4-5$ & 0.107 & 0.547 & 0.373 & 0.099 \\
\hline $6+^{\star}$ & - & - & - & - \\
\hline \multicolumn{5}{|l|}{ Ethnicity } \\
\hline Luhya & -0.159 & 0.561 & -0.272 & 0.438 \\
\hline Luo & 0.036 & 0.913 & -0.149 & 0.726 \\
\hline Teso* & - & - & - & - \\
\hline \multicolumn{5}{|l|}{ Religion } \\
\hline Catholic & -0.022 & 0.876 & -0.030 & 0.867 \\
\hline Other* & - & - & - & - \\
\hline \multicolumn{5}{|l|}{ Level of education } \\
\hline$<$ Secondary & -0.153 & 0.371 & -0.176 & 0.415 \\
\hline Secondary $+^{*}$ & - & - & - & - \\
\hline \multicolumn{5}{|l|}{ Partner's level of education } \\
\hline$<$ Secondary & 0.040 & 0.775 & -0.120 & 0.505 \\
\hline Secondary $+^{*}$ & - & - & - & - \\
\hline \multicolumn{5}{|l|}{ Reads newspapers or magazines } \\
\hline Yes & 0.172 & 0.289 & 0.297 & 0.151 \\
\hline $\mathrm{No}^{*}$ & - & - & - & - \\
\hline \multicolumn{5}{|l|}{ Listens to radio } \\
\hline Yes & 0.130 & 0.459 & 0.263 & 0.261 \\
\hline $\mathrm{No}^{*}$ & - & - & - & - \\
\hline \multicolumn{5}{|l|}{ Watches television } \\
\hline Yes & -0.060 & 0.711 & 0.090 & 0.659 \\
\hline $\mathrm{No}^{*}$ & - & - & - & - \\
\hline \multicolumn{5}{|l|}{ Discussed use of FP with spouse } \\
\hline Yes & 0.393 & 0.006 & 0.627 & 0.001 \\
\hline $\mathrm{No}^{*}$ & - & - & - & - \\
\hline \multicolumn{5}{|l|}{ Type of FP method being used } \\
\hline None & -0.357 & 0.016 & -0.568 & 0.004 \\
\hline Short-acting & 0.053 & 0.783 & 0.055 & 0.815 \\
\hline \multirow{2}{*}{\multicolumn{5}{|c|}{ District }} \\
\hline & & & & \\
\hline Bondo & -0.228 & 0.503 & 0.216 & 0.622 \\
\hline Siaya & -0.406 & 0.201 & 0.346 & 0.397 \\
\hline Busia & -0.158 & 0.551 & 0.262 & 0.441 \\
\hline Teso* & - & - & - & - \\
\hline Intercept 1 & -1.810 & 0.000 & -2.885 & 0.000 \\
\hline Intercept 2 & 0.383 & 0.227 & 1.920 & 0.000 \\
\hline$\chi^{2}$ value & 37.756 & 0.006 & 65.236 & 0.000 \\
\hline df & 19 & - & 19 & - \\
\hline
\end{tabular}

impact of FP on the child than women who did not discuss FP with their partner and were not using a method of FP.

Although they did not have the strongest association, ethnicity and district were also significantly associated with knowledge about the impact of using FP on the child. The Luhya women had the highest $(38 \%)$ level of knowledge, followed by the Teso women $(35 \%)$. By district, women from Busia district $(39 \%)$ had the highest knowledge levels, followed by women from Bondo district $(35 \%)$. Access to the media and religion had no significant effect on the knowledge about the impact of FP 
on the child. Knowledge about the impact of FP on the mother was significantly associated with all independent variables except partner's education level. Religion and access to the media, which were of no significance on the knowledge regarding the impact of FP on the child, showed significance on the level of knowledge about the impact of FP on the mother.

\section{Determinants of knowledge about the impact of using FP methods on the child}

Results on the determinants of knowledge about the impact of using FP on the child are presented under Model I of the ordered logit in table 5. Only two variables are significant on knowledge about the benefits of FP for the child. These variables are 'discussed use of FP' $(p<0.007)$ and 'type of FP method' being used $(p<0.02)$. Women who discussed FP with their partner have higher knowledge about the benefits or impact of FP on the child than those who did not. Women who are not using a method of FP have lower knowledge about the impact of FP on the child than women using long-acting or permanent methods of FP. The model also shows that there are no significant differences in knowledge levels between women using short-acting methods of FP and women using long-acting or permanent methods of FP.

\section{Determinants of knowledge about the impact of using FP methods on the mother}

Model II in table 5 shows the determinants of knowledge about the impact of FP on the mother or woman. As in Model I, 'discussed use of FP' and 'type of FP method' being used are significant for a woman's level of knowledge about the impact of FP on the mother. These variables actually show stronger significance for knowledge about benefits for the mother than for the child. However, unlike Model I where age of the woman is insignificant, Model II shows that the age $(p<0.002)$ of a woman is a strong predictor of knowledge about the impact of FP on the mother. Young women (aged 1524) are significantly less likely to have higher knowledge about the impact of FP on the mother than older women (aged 40-49). There is no significant difference in knowledge levels between middle aged women (aged 25-39) and older women (aged 40-49).

\section{DISCUSSION}

This paper has examined the level of knowledge regarding the benefits of FP and has also analysed factors associated with this knowledge. Knowledge levels about the impact of FP are generally low, as less than $40 \%$ of women in Western Kenya reported high knowledge about the impact of FP on the child, while approximately $16 \%$ were highly knowledgeable about the impact on the mother.

According to women's characteristics, only three out of the 12 variables examined are significant predictors of knowledge about the benefit of FP. The strongest predictor is the discussion of FP with the spouse. This variable was significant for knowledge about the impact on both the child and mother. Discussion of FP with the spouse has been found to be critical in the use of FP methods elsewhere. Several studies have shown that women who discuss with their spouses about, and have their partner's approval for, FP are more inclined to use a modern method of contraception. ${ }^{13}{ }^{16-18}$ For example, Ethiopian women who discussed FP with neither their husbands nor a health worker had the highest unmet need for FP. ${ }^{13}$ In this study, women not using contraceptive methods are less knowledgeable about the benefits of FP; this is expected as individuals are less likely to adopt behaviours for the sake of change without anticipating some benefits from such behaviour. Age was only significant on the knowledge about benefits for the mother. Younger women were less knowledgeable about the benefits of FP compared with older women (aged 40-49). Generally, older women are more experienced about reproductive health matters than younger women, hence this observation.

The interpretation of the findings in this study needs to be done with caution as the study uses cross-sectional survey data. To this end only associations, and not causal relationships between variables and outcomes, can be accounted for. This limitation is accentuated with a lack of qualitative information to complement the findings.

\section{CONCLUSION}

This study has demonstrated that women in the study area have low knowledge about the benefits of FP for themselves and their children. Therefore, FP interventions need to emphasise increasing knowledge about the benefits of FP among women in Western Kenya. These interventions should also involve men as they are critical in influencing women's decisions regarding FP.

Acknowledgements We are grateful to the Evidence to Action (E2A), Partnerships for Maternal, New-born, and Child Health (PAMANECH) and PWKP Projects for supporting our work.

Contributors NM partly conceptualised the study, ran the statistical analysis and wrote part of the first draft of the manuscript. PB took part in the conceptualisation of the study and interpretation of the data, managed the literature searches and wrote part of the first draft of the manuscript. CM was involved in the interpretation of the data and contributed to further development of the manuscript. EK contributed to the literature searches. All the authors read, reviewed and approved the final manuscript.

Funding PWKP is financed by the David and Lucile Packard Foundation. The funders were not involved in the decision to write this paper.

Competing interests None.

Ethics approval Kenya Medical Research Institute (KEMRI).

Provenance and peer review Not commissioned; externally peer reviewed.

Data sharing statement The data set can be obtained from Michael Mutua (mmutua@aphrc.org).

Open Access This is an Open Access article distributed in accordance with the Creative Commons Attribution Non Commercial (CC BY-NC 3.0) license, which permits others to distribute, remix, adapt, build upon this work noncommercially, and license their derivative works on different terms, provided the original work is properly cited and the use is non-commercial. See: http:// creativecommons.org/licenses/by-nc/3.0/ 


\section{REFERENCES}

1. Kenya National Bureauof Statistics (KNBS)., I. Kenya Demographic and Health Survey 2008-09. Calverton, Maryland: KNBS and ICF Macro, 2009.

2. Ojakaa D. Trends and determinants of unmet need for family planning in Kenya. DHS Working Papers No. 56. Calverton, MD: Macro International, Inc, 2008.

3. Smith R, Ashford L, Gribble J, et al. Family planning saves lives. Washington, DC, USA: Population Reference Bureau, 2009.

4. WHO. Health Benefits of Family Planning. 1999 [cited 18 September 2013].

5. Moreland S, Talbird S. Achieving the millennium development goals: the contribution of fulfilling the unmet need for family planning. Washington, DC: Constella Futures, POLICY, 2006.

6. PAI. The key to achieving the millennium development goals: universal access to family planning and reproductive health: Washington, DC: Population Action International, 2010.

7. Republic, o., Kenya. Kenya Vision 2030 The Popular Version. Nairobi: Government Printer, 2007.

8. Cleland JG, Ndugwa RP, Zulu EM. Family planning in sub-Saharan Africa: progress or stagnation? Bull World Health Organ 2011;89:137-43.

9. Nangendo SM. Knowledge and use of family planning methods and services in West Yimbo Division, Bondo district, Western Kenya. Afr Stud Monogr 2012;33:233-51.
10. Odimegwu CO. Family planning attitudes and use in Nigeria. Int Fam Plan Perspect 1999;25:86-91.

11. Terefe A, Larson CP. Modern contraception use in Ethiopia: does involving husbands make a difference? Am J Public Health 1993;83:1567-71.

12. Korra A. Attitudes towards family planning, and reasons for nonuse among women with unmet need for family planning in Ethiopia. Calverton, Maryland, USA: ORC Macro, 2012.

13. Tilahun $\mathrm{T}$, Coene $\mathrm{G}$, Luchters $\mathrm{S}$, et al. Family planning knowledge, attitude and practice among married couples in Jimma Zone, Ethiopia. PLOS ONE 2012;8.

14. Allison DP. Logistic regression using SAS: theory and application. Cary, USA: SAS Institute Inc, 1999.

15. Hosmer WD, Lemeshow S. Applied logistic regression. Toronto: John Wiley \& Sons Inc, 2000

16. Cox S, Posner SF, Sangi-Haghpeykar H. Who's responsible? Correlates of partner involvement in contraceptive decision making. Women's Health Issues 2010;20:254-9.

17. Yue K, O'Donnell C, Sparks PL. The effect of spousal communication on contraceptive use in Central Terai, Nepal. Patient Educ Counse 2010;81:404-8.

18. Mutombo N, Bakibinga P. The effect of joint contraceptive decisions on the use of long-acting and permanent methods among married female (15-49) contraceptive users in Zambia: a cross-sectional study. Reproductive Health (Under review), 2013. 